Article

\title{
Measurement Method and Empirical Research on the Sustainable Development Capability of a Regional Industrial System Based on Ecological Niche Theory in China
}

\author{
Hang Yin ${ }^{1, \dagger, *}$, Qing He ${ }^{1, \dagger}$, Tao Guo ${ }^{1, \dagger}$, Jianxin Zhu ${ }^{1, \dagger}$ and Botao Yu ${ }^{2, \dagger}$
}

1 School of Economic and Management, Harbin Engineering University, 145 Nantong Street, Harbin 150001, China; E-Mails: qingheheu1988@163.com (Q.H.); guotaohrbeu@126.com (T.G.); Zhujx1971@yeah.net (J.Z.)

2 School of Economic and Management, Northeast Forestry University, 26 Hexing Road, Harbin 150040, China; E-Mail: Botao_YU@126.com

$\dagger$ These authors contributed equally to this work.

* Author to whom correspondence should be addressed; E-Mail: yinhang@hrbeu.edu.cn; Tel.: +86-451-5764-2707; Fax: +86-451-8251-9916.

External Editor: Marc A. Rosen

Received: 24 June 2014; in revised form: 17 November 2014 / Accepted: 19 November 2014 / Published: 25 November 2014

\begin{abstract}
From the analytical view of a recycling economy, the regional system achieves the goal of sustainable development through improving resource utilization efficiency, reducing energy consumption and ameliorating the quality of water and air. The regional economic system's potential for sustainable development is significantly influenced by regional industrial operational efficiency, which measures the cost of ecology, environment, energy and resources accompanying the economic growth. It is vital for national and regional governments to accelerate harmonious development between products of industrial department, consumption of energy and pollutants discharged. Under the guidance of ecological niche theory and recycling economy theory, the theoretical analysis on efficient relations between regional industrial growth, energy consumption, resources utilization and environmental carrying capacity has been carried out from horizontal and vertical respects. Industrial operational efficiency and the sensitivity coefficient in response to the change of every input and output index can be calculated and critical factors, which restrict sustainable development capability, can be found out so that quantitative references could be provided for administrative decisions. As for the measurement method, a super efficiency mixed data envelopment
\end{abstract}


analysis model, which wipes off self-limited condition and either contains both meeting cone characteristic indexes or not, has been established and applied. Statistics from 1993 to 2012 in China are collected to carry out empirical research. On the basis of further analysis, an adjustment strategy can be constituted to improve the capability for sustainable development.

Keywords: sustainable development capability; industrial system; ecological niche; industrial operational efficiency; empirical research

\section{Introduction}

The regional system is a complicated combination, which consists of economic, ecological and social sub-systems. The ecological sub-system is the basis, the economic sub-system is the guidance and the social sub-system is the carrier. The essence of regional system's development is the mutual function between environmental carrying capacity and resource consumption volume, which reflects the spiral rising process from primary extensive developmental mode to advanced cooperative and symbiotic developmental mode [1-4]. In the last several decades, most regional systems operated with the extensive developmental mode in order to achieve the single goal of increasing industrial output. The extensive developmental mode brought out serious vulnerability of economic, ecological and social sub-systems, and the Butterfly Effect gradually became significant. Considering the severe consequences mentioned above, academic scholars began to pay close attention to the negative environmental effects caused by economic growth. Representative scholars such as Grossman and Krueger (1991) [5] introduced the Kuznets Curve into the research of the relation between environmental pollution and economic growth of the regional system. From then on, many scholars applied the Environmental Kuznets Curve in the comparative analysis on national environmental quality and economic growth of different countries [6-12]. At present, plenty of scholars have carried out relative analysis and empirical research based on statistics from China, and the results indicate that the turning point of the environmental Kuznets Curve has not been reached [13-16]. For a long time, the central and regional governments of China have excessively concentrated on rapid economic growth, but have ignored serious environmental pollution and unrecoverable destruction of ecological function. The developmental objectives of economic, ecological and social subsystems cannot be validly integrated so that non-cooperative conflicts permanently exist. On the one hand, the volume of waste gas and solid increased from 1993 to 2012 (according to Table 1), and energy consumption also displayed a gradual incremental tendency, which reflects an emergent threat from limited capacity of natural resources (according to Figure 1). On the other hand, the volume of waste water and consumption of water reflect a different trend as the water consumption reached its peak in 1998. From then on, the Chinese government implemented strict policies on water saving and waste water discharge, and the water consumption was reduced and limited on a reasonable level. However, the volume of waste water presented an uncontrolled rise from 2003 owing to the rapid economic growth and the scarcity of efficient sewage disposal techniques (according to Table 1 and Figure 2).

In Figure 1, the $X$ axis represents the analytical year (every graduation represents different analytical year from 1993 to 2012), and the $Y$ axis represents the volume of energy consumption (every graduation 
represents five hundred million tons of standard coal with the maximum of forty hundred million tons of standard coal) and the dots represent volume of energy consumptions of different analytical years (million tons of standard coal). In Figure 2, the $X$ axis represents the analytical year (every graduation represents different analytical year from 1993 to 2012), the $Y$ axis represents the volume of water consumption (every graduation represents a hundred billion cubic meters with the maximum of eight hundred billion cubic meters) and the dots represent the volume of water consumption of different analytical years (million cubic meters). The negative effect of economic growth with extensive developmental mode which weakens environmental sustainable development capability is accumulating. If the negative tendency is still not kept under control, the regional comprehensive system will inevitably collapse. As a pacemaker of the complicated system, the negative and positive effects of the economic sub-system will result in different developmental tendencies. Positive driving effects should be significantly utilized to guarantee cooperative development of three sub-systems so as to improve sustainable development capability of the regional system. According to the statistics from China, the proportion of manufacturing industry output to regional gross industry output is thirty five percent, and thirty percent of employers come from industry system. These two indexes are rising gradually in recent years. Growth mode of manufacturing industry directly affects operational efficiency of economic system and the cost of ecology, environment, resources and energy [17-20]. From the analytical view of input and output efficiency evaluation, the sustainable development capability of regional manufacturing industry can be measured with the application of super efficiency mixed DEA model based on unchanged output. Through further analysis of evaluation results, growth potential and sustainable development capability can be measured so as to find out critical influential factors which weaken operational efficiency of manufacturing industry. The core academic value of our research is to provide scientific and practical quantitative analytical method for measuring vulnerability of regional manufacturing industry so as to improve operational mode and efficiency. Therefore, the government can carry out scientific and quantitative reference suggestions of following adjustment strategy. It is obviously essential to provide some schemes for promoting the environmental sustainable development capability of regional comprehensive system in China.

The process of spiral improvement from the elementary extensive mode to the advanced intensive mode is the core of regional development, which reflects mutual function between resources support and consumption. Most regions in China concentrated on production increment with the expense of environmental destruction in the last several decades. The serious pollution and destruction of non-renewable resources forced the Chinese government to optimize the economic growth mode. The sustainable and environmental economic growth theory will be analyzed and discussed in Section 2 of this paper. Based on the growth model with environmental elements set up in Section 2, the ecological niche concept can highly simulates the mutual gaming relations and evolutionary process between different categories of executive subjects and environmental elements in social and economic area, these contents will be introduced in Section 3, and the relation between industry operational efficiency and environmental capacity will be emphasized and discovered with the consideration of the industry's importance in the economic system. Furthermore, measurement dimensions, principles and model which can evaluate the degree of the effect on environment caused by industry operation will be constructed and the empirical research will be carried out based on the statistics from China in Sections 4 and 5. 
According to the empirical results, the reasons for serious environmental destruction will be found out and administrative adjustment strategies will be provided.

Table 1. Volume of waste water, waste gas and waste solid from 1993 to 2012 in China.

\begin{tabular}{ccccc}
\hline Year & $\begin{array}{c}\text { Annual GDP } \\
\text { of China } \\
\text { (Billion RMB) }\end{array}$ & $\begin{array}{c}\text { Volume of Waste } \\
\text { Water (Million } \\
\text { Cubic Meters) }\end{array}$ & $\begin{array}{c}\text { Emissions of } \\
\text { Waste Gas } \\
\text { (Thousand Tons) }\end{array}$ & $\begin{array}{c}\text { Emissions of } \\
\text { Solid Waste } \\
\text { (Thousand Tons) }\end{array}$ \\
\hline 2012 & 51932.23 & 67489.39 & 23066.64 & 31596.83 \\
2011 & 47310.41 & 65919.22 & 22179.13 & 33282.52 \\
2010 & 40151.28 & 61725.62 & 21851.53 & 34928.62 \\
2009 & 34090.28 & 58908.77 & 22144.04 & 44998.43 \\
2008 & 31404.54 & 57168.01 & 23212.02 & 51253.22 \\
2007 & 26581.03 & 55684.94 & 24680.94 & 57815.11 \\
2006 & 21631.44 & 51448.02 & 25888.03 & 70941.43 \\
2005 & 18493.74 & 52450.89 & 25494.02 & 75235.92 \\
2004 & 15987.83 & 48240.94 & 22549.03 & 74289.51 \\
2003 & 13582.28 & 46710.84 & 24213.11 & 86269.31 \\
2002 & 12033.27 & 46619.80 & 24227.83 & 94637.04 \\
2001 & 10965.52 & 47553.89 & 25480.63 & 103816.32 \\
2000 & 9921.46 & 48310.97 & 26607.43 & 113886.02 \\
1999 & 8967.71 & 49030.37 & 27755.92 & 124932.43 \\
1998 & 8440.23 & 54436.43 & 32657.84 & 128230.12 \\
1997 & 7897.30 & 53635.51 & 32218.83 & 128839.22 \\
1996 & 7117.66 & 52467.20 & 30722.91 & 142668.31 \\
1995 & 6079.37 & 51814.53 & 30149.31 & 159683.91 \\
1994 & 4819.79 & 45996.98 & 28337.92 & 164929.01 \\
1993 & 3533.39 & 37535.41 & 23929.23 & 178996.74 \\
\hline
\end{tabular}

Figure 1. Volume of energy consumption from the year of 1993 to 2012 in China.

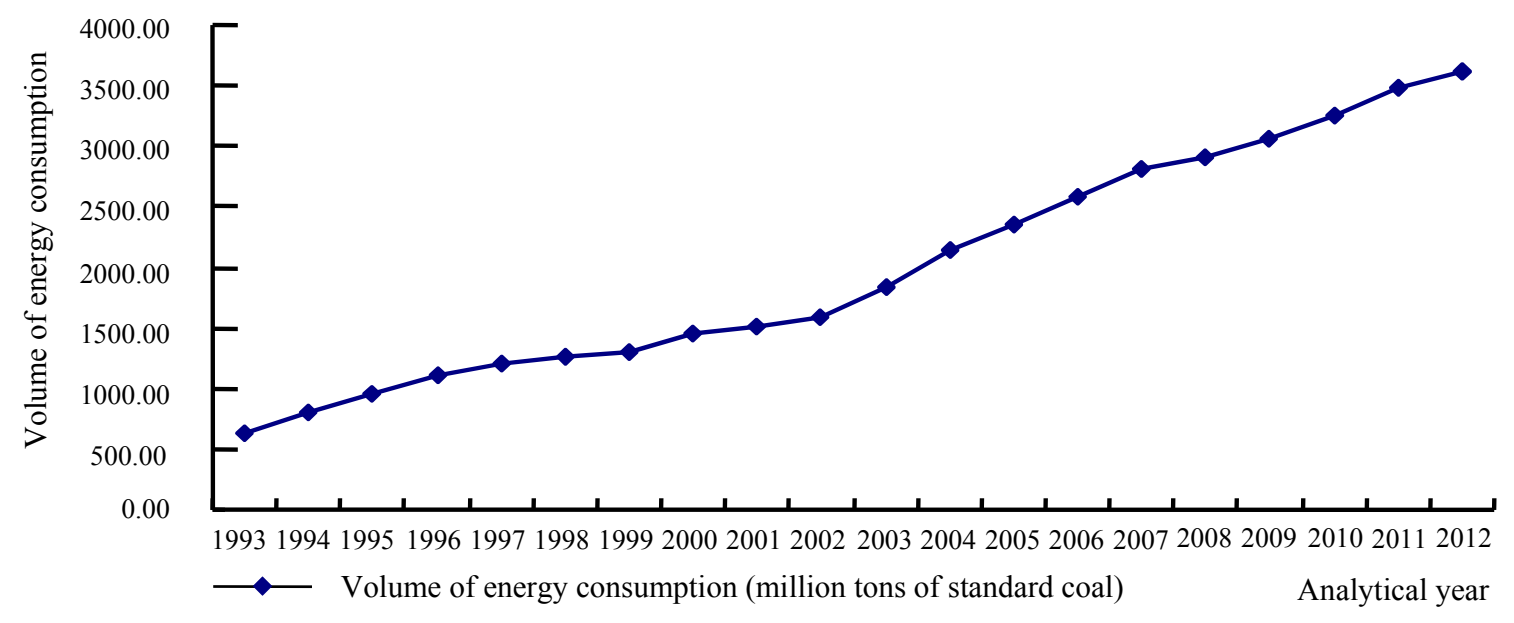


Figure 2. Volume of water consumption from the year of 1993 to 2012 in China.

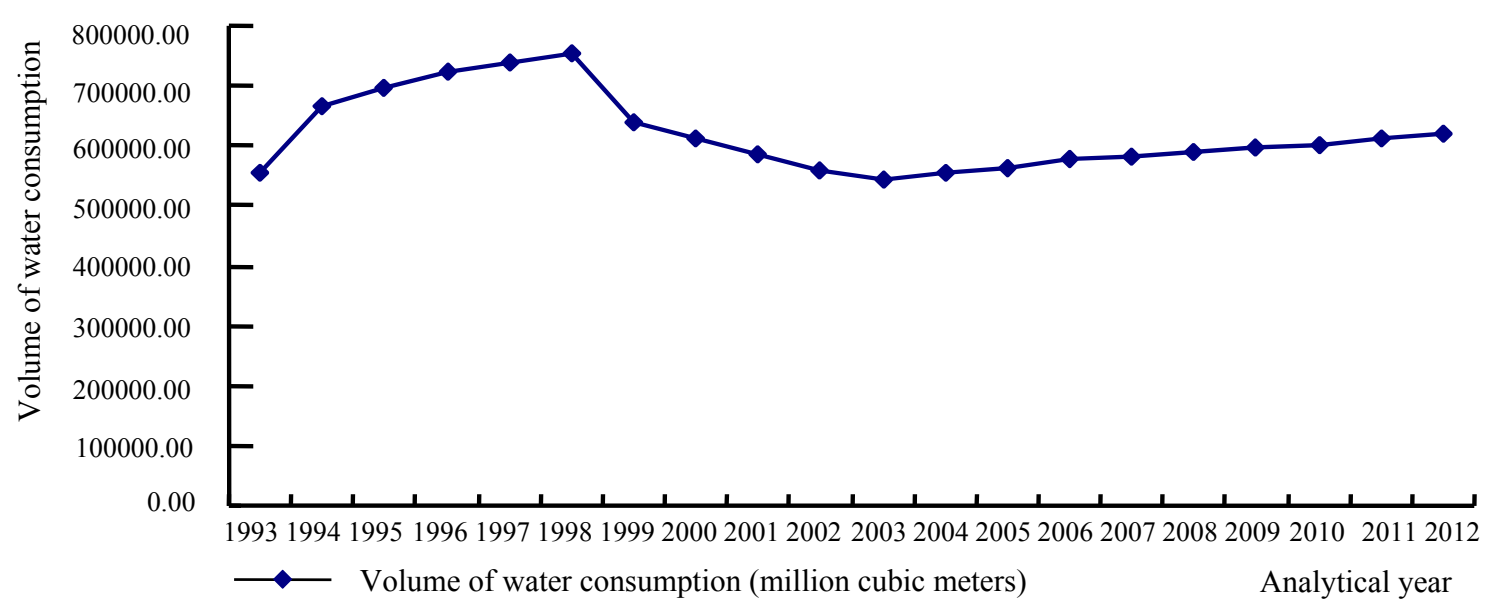

\section{Economic Growth Theory}

Practical economic growth in most developed countries indicates that environmental regulations help to accelerate the improvement of production efficiency, stimulate the technical innovation and work out a significantly positive effect on economic growth in the long term. The Theory of Endogenous Growth advanced by the scholar Romer (1986) [21] emphasized that the comprehensive effects were caused by the accumulation of knowledge capital and human capital. The comprehensive effects can be defined as radiant effects of technical progress. In the Romer model, money capital $(C)$, labor $(L)$, human capital $(H)$ and knowledge capital $(K)$ are four fundamental input resources. Based on the modified Romer model carried out by Yin Jing [22] and He Jun [23], pollution strength has been introduced into production function in which the parameter $p(p \in[-\infty,+\infty])$ represents pollution coefficient which measures pollution degree accompanying economic growth [24-26]. When the parameter $p$ is greater than or equal to the value 1.0, it means that environment is a driving element which accelerates economic growth. If not, it means that the practical output is lower than potential output and may bring about negative results. The production function with environmental elements can be defined and described as the Equation (1). The change of environmental quality is affected by two categories of factors [27]. The former is the environmental depravation caused by pollution emission, and the latter are self-repairing capacity of environment (which is represented by the parameter $r_{t}$ ) and man-made repairing capacity (which is represented by the parameter $p_{t}$ ). The present environmental quality is significantly affected by the comprehensive function of these two categories of factors. The parameter $r_{t}$ represents self-repairing capacity coefficient of environmental level of the period $E_{(t-1)}$ in the present time (the period $t$ ), and the function of present environmental level is described as the Equation (2).

$$
\begin{gathered}
G_{(t)}=K_{(t)}^{\alpha+\beta} \times H_{(t)}^{\alpha} \times L_{(t)}^{\beta} \times C_{(t)}^{\gamma} \times p_{(t)} ; \alpha+\beta+\gamma=1 ; \alpha, \beta, \gamma>0 \\
E_{(t)}=E_{(t-1)} \times p_{(t)}+r_{(t)}
\end{gathered}
$$

The growth model with environmental elements makes further contribution to the Theory of Endogenous Growth. Based on the comprehensive analysis of Equations (1) and (2), the relation between the economic growth level of present period (which is represented by the variable $\Delta G$ ) and environmental level of the present period driven by $\Delta G$ (which is represented by the variable $\Delta E$ ) can be described as the Equation (3). 
In this equation, $\theta=p_{(t)}+r_{(t)}=f(K, H, L, C, M)+r$, the variable $C$ represents the money capital, the variable $L$ represents the labor, the variable $H$ represents the human capital, the variable $K$ represents the knowledge capital, the variable $M$ represents the effect brought out by economic policy and legal regulation to improve the environmental quality. The correlative functions $(\theta)$ between economic growth level $(\Delta G)$ and environmental level $(\Delta E)$ of different regions at different time are distinguishing, and the combination relations of $\Delta G$ and $\Delta E$ can be shown as the scattered dots in Figure 3. In Figure 3, the $X$ axis represents the economic growth level (which is represented by the variable $\Delta G$ ), the $Y$ axis represents the environmental level (which is represented by the variable $\Delta E$ ) driven by the economic growth level $(\Delta G)$, the dots represent different sets of the economic growth level $(\Delta G)$ and the environmental level $(\Delta E)$, Region I reflects that the economic growth level is positive and the environmental level is positive $(\Delta E>0, \Delta G>0)$, Region II reflects that the economic growth level is positive and the environmental level is negative ( $\Delta E<0, \Delta G>0$ ), Region III reflects that the economic growth level is negative and environmental level is negative $(\Delta E<0, \Delta G<0)$ and Region IV reflects that the economic growth level is negative and the environmental level is positive $(\Delta E>0, \Delta G<0)$. The angle $\alpha$ is formed by the line linking the scattered dot with the point of origin and the horizontal axis. Its tangent value is determined by the correlative function $(\theta)$ which reflects the relation between economic growth level $(\Delta G)$ and environmental level $(\Delta E)$. To sum up, environmental elements and technical progress should be considered as endogenous driving forces in whether short-term or long-term economic growth model [28]. Considering the mentioned developmental concept, the people should redefine and explain the connotation of industrial and regional sustainable economic growth in a new approach.

$$
\Delta E=E_{(t)}-E_{(t-1)}=\Delta G \times \theta=\left(G_{(t)}-G_{(t-1)}\right) \times\left[f\left(K_{(t)}, H_{(t)}, L_{(t)}, C_{(t)}, M_{(t)}\right)+r_{(t)}\right]
$$

Figure 3. Mutual analysis figure of economic growth level and environmental level.

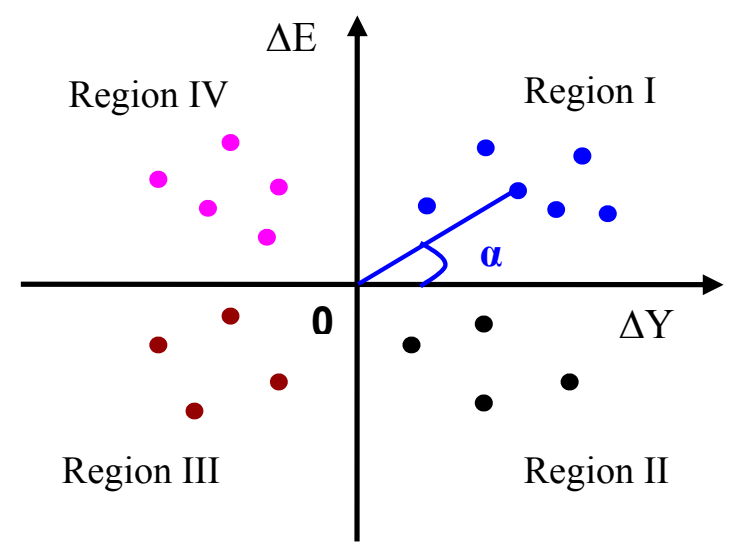

$\Delta \mathrm{Y}$ : Economic growth level $\Delta \mathrm{E}$ : Environmental level

Region I: $\Delta \mathrm{E}>0, \Delta \mathrm{Y}>0$, economic growth is positive and environmental level is positive

Region II: $\Delta \mathrm{E}<0, \Delta \mathrm{Y}>0$, economic growth is positive and environmental level is negative

Region III: $\Delta \mathrm{E}<0, \Delta \mathrm{Y}<0$, economic growth is negative and environmental level is negative

Region IV: $\Delta \mathrm{E}>0, \Delta \mathrm{Y}<0$, economic growth is negative and environmental level is positive

\section{Evolutionary Capability of Industrial Ecological Niche}

The ecological niche reflects the position and function of biological organisms in the living environment which contain conditions and resources required for survival during special periods. It is an assemblage of selective range for every kind of organism towards resources and environment. The ecological niche, which represents mutual function relations between biological organisms and the living environment, highly simulates the mutual gaming relations and evolutionary process of gradual integration of different categories of executive subjects and environmental elements in social and 
economic systems. Guided by Ecological Niche Theory, many scholars have carried out a series of creative achievements such as researches on dynamic mechanism of knowledge innovation in virtual enterprises [29,30], researches on evolutionary mechanism of enterprise technical capability [31,32], analyses and measurements of core capability of research-based institutions [33], researches on the relation between competition exclusion of enterprise and environmental change [34,35], researches on evolutionary process of structural change of metropolitan area [36,37] and researches on the ecological niche of regional industrial clusters [38-42]. Most scholars have emphasized mutual relation research between different executive subjects and living environment but ignored introducing environmental elements into the economic and social function relations among different relevant subjects. Present research achievements cannot systematically reflect coordinative development between economic organisms and the environmental capacity. The Ecological Niche Theory is introduced to redefine connotation of industrial ecological niche which greatly contributes to sustainable development research. The developmental mode of industry system is driven by the gaming and integration of economic and ecological factors such as natural resource, capital resources and human resources through industrial techniques, industrial organization and industrial structure. According to Figure 3, the correlative function $(\theta)$ reflects the relations between economic growth level $(\Delta G)$ (which is principally decided by industrial operation) and environmental level $(\Delta E)$. Furthermore, it brings out strong dynamic coupling relations of economic growth and ecological environment which is highly similar to the relations between biological organisms and living environment. The industry system brings out two categories of feedback effects on the natural environmental system. One represents the negative feedback caused by ecological damage and the other represents the positive feedback caused by ecological restoration. The gaming results of two feedback effects represent the evolution or the degeneration which reflects another symbol of ecological niche.

\subsection{Connotation Definition of Industrial Ecological Niche}

Industrial operational efficiency is a core element, which significantly affects the regional ecological niche. In the past several decades, many scholars have attached importance to the environmental effect caused by industrial operation. In 1991, economists in the United States (Grossman and Krueger) [5] introduced the inverted-U hypothesis (which is advanced by the scholar Simon Smith Kuznets) [7] into the relation research between environmental pollution and economic growth, and made use of inverted-U curve to represent the Environmental Kuznets Curve (EKC) [8,9,43,44]. In 1992, the scholar Shafik applied EKC in comparative analysis on relations between economic growth and environmental quality in different countries, empirical results (which were advanced in "World Development Report 1992") verified the existence and scientificity of the Environmental Kuznets Curve [45]. In addition, some scholars carried out empirical research on many categories of pollutants in developed countries to verify the existence of EKC [46]. Nowadays, more and more scholars have shown eager interests in EKC analysis and empirical research based on the statistical data from China. Some scholars carried out analysis on the change trends of national discharge of the three wastes (waste water, waste gas, and waste residue) [47-49], some other scholars carried out empirical research on many categories of pollutants in different provinces of China [50-53]. The empirical results indicated that the EKC turning point of industrial pollutants discharge has not been met in China, extensive industrial operational mode with the 
expense of ecological environment damage brought out monotone increasing cubic curve shape and even backward curve shape of national industrial EKC in some regional industrial systems [13-16,54,55]. With the guidance of the Ecological Niche Theory, restructuring positive-U curve shape of regional industrial Environmental Kuznets Curve is beneficial to achieve coordinative and sustainable developmental objective of industrial operation and environmental quality.

Similar to the relation of organism and living environment, there is mutual reliance and mutual restriction relations between regional industries and ecological environment. Organic, ecological connected and systemic concepts can be applied in describing the relation of industries and environment under the guidance of research framework of ecology. For the precise orientation of the industrial ecological niche in complicated and dynamic environments, the industry system should independently learn and recognize a living environment to carry out adaptive and purposeful restructuring for achieving metabolism of industry system and evolution of industrial ecological niche. According to the connotation of ecological niche and relation characteristics between industry system and living environment, industrial ecological niche can be described as relative position and special function which are formed during the dynamic mutual process between industry system and living environment. The industrial ecological niche reflects the gaming and integrating driven by industrial ecological factors such as natural resources, capital resources and human resources through industrial organization, industrial techniques and industrial structure. The above-mentioned process will form a special industrial operational mode. There are two primary aspects of macro-control during the process, the former represents internal administration and integration of industry system, and the latter represents adaptation and feedback towards external environment.

\subsection{Evolutional Sequence Analysis of Industrial Ecological Niche}

The evolution of the industrial ecological niche represents gradual progress and development. Comparing with biological evolution, industrial evolution has a strong purposefulness. Two principal factors force industry system to change growth mode, the first factor is the limitation of resources, which cannot support larger scale of production with initial low manufacturing efficiency, and the second factor is the limitation of environmental capacity, which cannot sustain extensive development without the expense of serious pollution of water, air, land and so on. People carry out adjustment strategies to promote manufacturing efficiency and reduce environmental damage caused by the industry system. In a word, the industrial techniques, industrial organization and industrial structure have been optimized according to the will of humans, the limitation of resources and environmental capacity. This phenomenon can be described as the evolution of the industrial ecological niche. The evolution of the industrial ecological niche, which has obvious directivity, is the process for industry system to restore the living environment, and the essence is the natural selection of organisms in the living environment, which can be defined as a large-scale industrial ecological engineering. Compared with the ecological niche evolution of natural organisms, the dominant function of human society plays an essential role in evolutionary process of industrial ecological niche so as to drive it gradual progress according to the initial manual orientation. The evolution of the industrial ecological niche is the voluntary and directed process of "variation-verification-conservation- propagation" for industry to suit the living environment. The change of the industry development mode and corresponding feedback of environment have 
formed evolutionary sequence of industrial ecological niche. It has a self-organizing, self-learning and self-innovating evolutionary capability for the transition of the industry system from a low-level to a high level ecological niche.

Similarly to absorption, digestion, excretion and nerve subsystems of natural organisms, the evolutionary process of industry system contains process from input resources to output productions. It is a dissipative structure which represents organic integration of internal and external elements. The industrial ecological niche has obvious hierarchies [56]. For a precise description, the industrial ecological niche of every hierarchy can be located on the same flat respectively which represents gaming and integrating of elements. Different hierarchies of industrial ecological niches are defined as an evolutionary sequence, and the evolutionary process of different hierarchies of industrial ecological niches is described in Figure 4. In Figure 4, the pink line with double-headed arrow reflects internal administration and feedback of industry system, the blue line with double-headed arrow reflects external adaptation and feedback of ecological environment, the black line with double-headed rhombus reflects gaming and integrating of natural, capital and human resources. Hierarchy I reflects extensive economic growth with the industry value centered, Hierarchy II reflects transitive economic growth with the consideration of ecology, Hierarchy III reflects intensive growth with the guidance of low carbon economy concept and Hierarchy IV reflects sustainable growth with the guidance of circular economy theory. NR represents natural resource, CR represents capital resource, HR represents human resources, IO represents industrial organization, IT represents industrial techniques, IS represents industrial structure and EC represents environmental capacity.

Figure 4. Sequential evolutionary sketch map of industrial ecological niche.

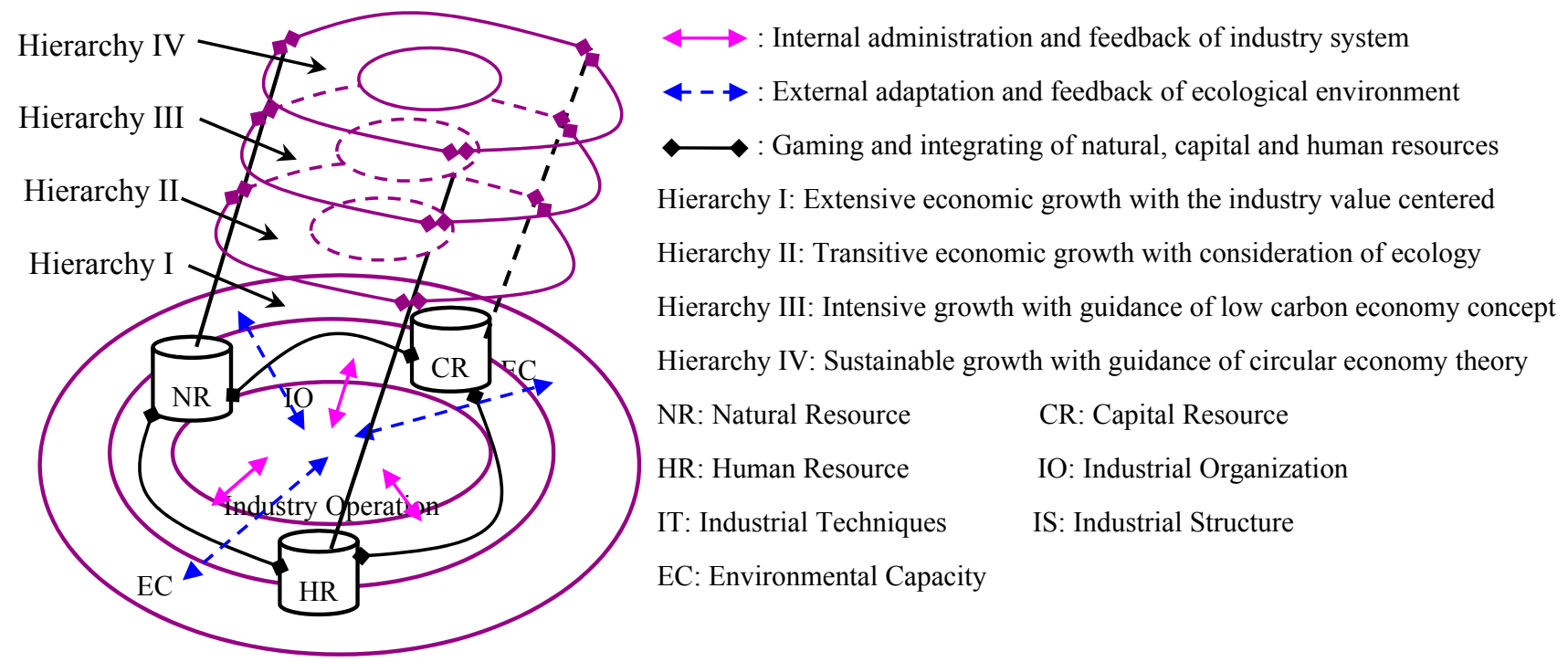

There are circular and catalytic relations between evolution and elements of industrial ecological niche. Evolution is the process which represents continuous gaming of elements and discontinuous transition among different hierarchies of industrial ecological niches. As a part of the ecological system, the initial hierarchy of industrial ecological niche perhaps would be weakened or eliminated. Accompanied by the disappearance of the original ecological niche and the emergence of the new ecological niche, the industry system will switch between different hierarchies of ecological niches 
(transit upward or downward) to avoid serious conflict between industrial operation and environmental capacity. The serious conflict surely would damage the sustainable development capability. As shown

in Figure 4, the higher the hierarchy of industrial ecological niche is, the broader the hierarchy of industrial ecological niche. In this situation, the position of industry system will become more superior and advantageous. The elements and relations would be improved accompanied with the switch and transition among different hierarchies of industrial ecological niches.

\section{Methods}

\subsection{Dimensions Analysis on Industrial Operational Efficiency}

According to the statistical data and Figure 4, the industry system of China remains at the second hierarchy of the industrial ecological niche (Hierarchy II: Transitive Growth, Considering of Ecology). It is a vital task for the central government to restructure and integrate natural resources, capital resources and human resources through the macro-control policies of industrial organization, industrial structure and industrial techniques [28]. The essential purpose is to improve evolutionary capability of industry system from Hierarchy II to Hierarchy III of industrial ecological niche [56]. The dimension structure of evolutionary ability can be described as in Figure 5. In Figure 5, the $X$ Axis represents sequence in time of industrial ecological niche's evolution, the $Y$ Axis represents damage degree of environmental capacity caused by industrial operation, the $Z$ Axis represents internal administrative and integrating degree of industry system, the Turning Point $C$ represents threshold point of environmental capacity, Region A reflects that damage force of industry is greater than restoration force of environment, Region $\mathrm{B}$ reflects that restoration force of environment is greater than damage force of industry, the pink line with double-headed arrow reflects internal administration and feedback of industry system, the blue line with double-headed arrow reflects external adaptation and feedback of ecological environment, the black line with double-headed rhombus reflects gaming and integrating of natural, capital and human resources.

Firstly, the dimension analysis of the resource. The width of the industrial ecological niche is determined by the ability to create a distinction between acquiring resources and different utilization efficiencies. It is essential for the industry system to improve the hierarchy of industrial ecological niche. Considering the characteristics of Hierarchy II, the bottle neck of resources is taking place.

It is serious that the environmental capacity is becoming weak and the ability to acquire resources is restricted during the period of transitive growth of the industry system. It is a practical route to improve utilization efficiency of acquired resources for broadening the width of present industrial ecological niche. According to Figure 5, the Turning Point $C$ can be broken through into Region B by the adjustment.

Secondly, the dimension analysis of adaptation. The improvement of the evolutionary capability of the industrial ecological niche occurs based on the special resource and under the peculiar situations of industry, ecology, administration and society. The adaptation dimension can be applied in analyzing the suitable degree of industry system towards internal and external multiple environments. The internal environment can be reconstructed to be more beneficial for improving evolutionary capability, while the industry system has no choice but adapting to external environments. The effect on the ecological environmental capacity caused by industrial operations should be paid close attention during the evolutionary process from Hierarchy II to Hierarchy III of industrial ecological niche. 
Thirdly, dimension analysis of integration. Efficient integration capability which can guarantee the stability makes contributions to avoid degeneration, and accumulate energy for the next transition after switching into the present higher hierarchy of industrial ecological niche. The improvement of the evolutionary capability of industrial ecological niche experiences the directed process of "variation-verification-conservation-propagation". There are plenty of continuous inferior hierarchies (according to Figure 5) among four principal hierarchies of industrial ecological niches (according to Figure 4). These continuous inferior hierarchies reflect spiral promotion and evolution, which can be described and measured by many analytical indexes. It is essential to monitor the achieving degree of important developmental objectives and make efficient adjustments during evolutionary process of industrial ecological niche for improving sustainable development capability.

Figure 5. Dimension structure of industrial ecological niche's evolutionary ability.

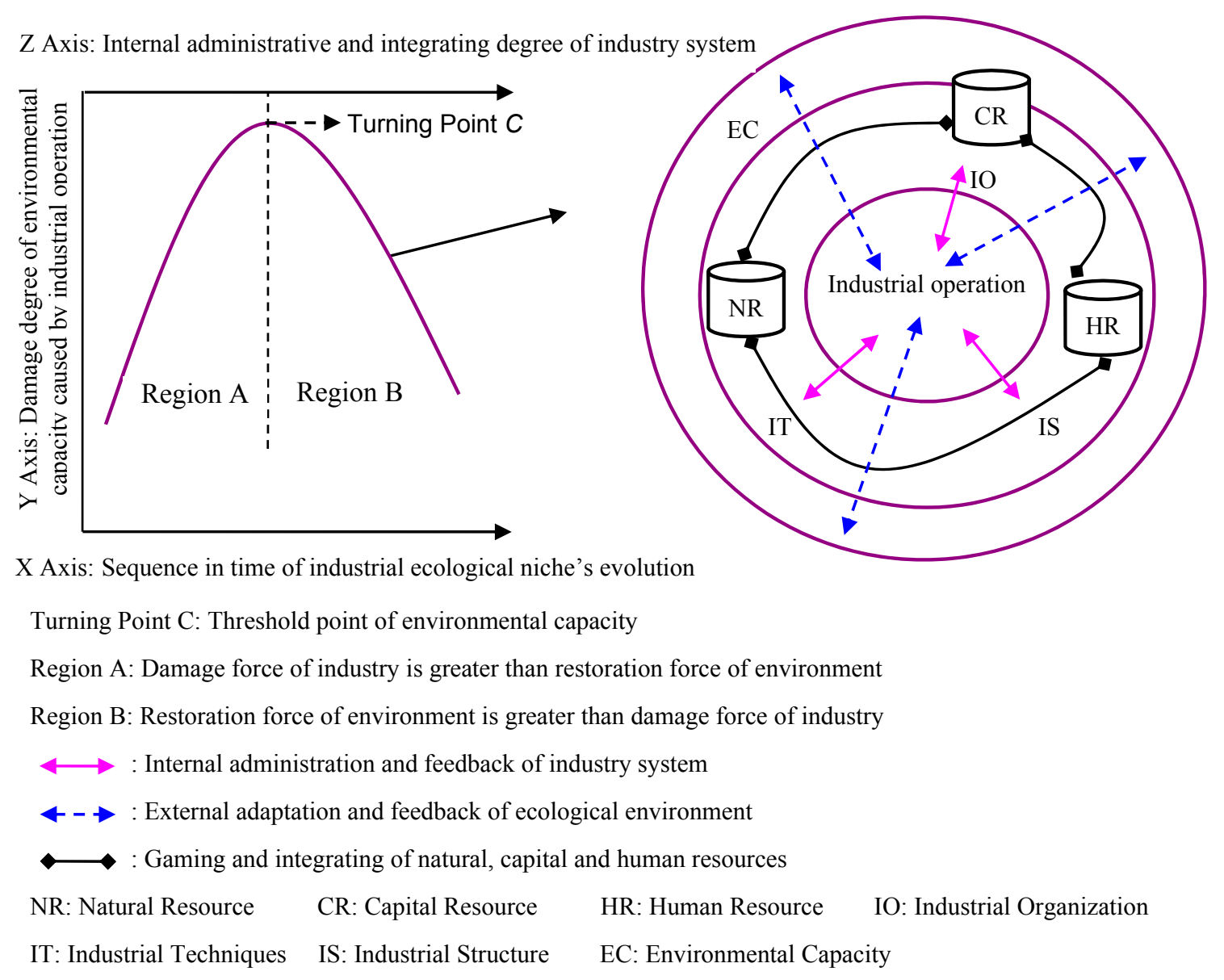

\subsection{Measurement Principles on Industrial Operational Efficiency}

According to dimension analysis on the evolutionary capability from Hierarchy II to Hierarchy III, national administrative institutions could set up evolutionary standard systems of ecological niche for different industries and regions. Considering the lack of authorized guiding standards, industrial operational efficiency which reflects the utilization efficiency of resources, the sustainability of economic growth and the effect degree on environmental capacity would be applied to dynamically measure the status of evolutionary capability. Therefore, measurement principles on industrial operational efficiency should 
be set up. Firstly, the principle of input-output efficiency. The measurement indexes that emphasize the correspondence of costs and benefits should be selected to carry out research on regional industrial operational efficiency from the view of input-output. Secondly, the principle of environmental cost. It is a creative analytical view to introduce the cost of environmental capacity in the measurement on the evolutionary capability of the industrial ecological niche. The measurement should reflect three-R effects such as reduction, re-utilization and recycling. Thirdly, principles of sensitiveness and logicality. The measurement should dynamically and predictably sense tiny variations and effects on the evolutionary capability of the industrial ecological niche during continuous process. Therefore, the sensitive and logical characteristics should be paid close attention. Fourthly, principles of practicability and conciseness. Considering the complexity of the evolutionary process, measurements would be hard to carry out and statistical data could not be acquired if all the influencing factors were involved. It is necessary to attach importance to refining indexes for improving maneuverability in practice.

\subsection{Measurement Indexes on Industrial Operational Efficiency}

Most indexes should be quantitative. Both absolute quantitative and relative quantitative indexes should be included. Several critical indexes should be selected to measure relative efficiency of evaluation objectives. According to the above-mentioned principles of measurement on industrial operational efficiency, ten measurement indexes can be set up shown as Table 2. Considering cone characteristics, which represent the quantity of input bringing out the proportional quantity of output, ten input-output indexes can be divided into two categories. Through analysis on the characteristics of indexes, the indexes such as annual industrial net value of capital asserts $\left(X_{1}\right)$, annual industrial average current assets $\left(X_{2}\right)$, work force of industry system $\left(X_{3}\right)$, annual exhaust emission of industry system $\left(X_{4}\right)$, annual unstandardized waste water of industry system $\left(X_{5}\right)$, annual unutilized solid waste of industry system $\left(X_{6}\right)$, annual energy consumption of industry system $\left(X_{7}\right)$, annual industrial productivity of industry system $\left(Y_{1}\right)$ and annual net profit of industry system $\left(Y_{2}\right)$ meet cone characteristic, these indexes can be described as $X=\left(X_{1}, X_{2}, X_{3}, X_{4}, X_{5}, X_{6}\right)$ and $Y=\left(Y_{1}, Y_{2}\right)$. The indexes such as return on total assets of industry system $\left(V_{1}\right)$ and overall staff working productivity of industry system $\left(V_{2}\right)$ do not meet cone characteristic, these indexes can be described as $V=\left(V_{1}, V_{2}\right)$. According to Table 2, input index 4 (annual exhaust emission of industry system, $X_{4}$ ), input index 5 (annual unstandardized waste water of industry system, $X 5$ ), input index 6 (annual unutilized solid waste of industry system) and input index 7 (annual energy consumption of industry system) are negative indexes which represent the environmental cost accompanied with economic growth. The values of industrial operational efficiency based on input and output indexes in Table 2 reflect pollution degree of environment and destruction degree of non-renewable resources. The higher the values of industrial operational efficiency are, the better the evolutional status of industrial ecological niches. The lower the values of industrial operational efficiency, the worse the evolutional status of industrial ecological niches are. 
Table 2. Measurement indexes on industrial operational efficiency.

\begin{tabular}{ll}
\hline \multicolumn{1}{c}{ Category of Indexes } & \multicolumn{1}{c}{ Measurement Indexes } \\
\hline input index 1 & annual industrial net value of capital assets $\left(X_{1}\right)$ \\
input index 2 & annual industrial average current assets $\left(X_{2}\right)$ \\
input index 3 & work force of industry system $\left(X_{3}\right)$ \\
input index 4 & annual exhaust emission of industry system $\left(X_{4}\right)$ \\
input index 5 & annual unstandardized waste water of industry system $\left(X_{5}\right)$ \\
input index 6 & annual unutilized solid waste of industry system $\left(X_{6}\right)$ \\
input index 7 & annual energy consumption of industry system $\left(X_{7}\right)$ \\
Output index 1 & annual industrial productivity of industry system $\left(Y_{1}\right)$ \\
Output index 2 & annual net profit of industry system $\left(Y_{2}\right)$ \\
Output index 3 & return on total assets of industry system $\left(V_{1}\right)$ \\
Output index 4 & overall staff working productivity of industry system $\left(V_{2}\right)$ \\
\hline
\end{tabular}

\subsection{Measurement Model on Industrial Operational Efficiency}

The relative efficiency measurement, generally carried out from the view of decision unit, is input and output efficiency. Nowadays, many scholars applied a single output index to measure the relative efficiency of decision units. Comparatively, the data envelopment analysis (DEA) method has advantages in dealing with multiple input and output research matters [57,58]. Through linear programming, the DEA model can decide if a corresponding point is situated on the valid manufacturing frontier so as to acquire much valuable administrative information. As an objective multiple indexes decision method, the DEA method does not need to confirm weight coefficients through subjective decisions so that measurement results can reflect the real status of decision units. It has been proved through the application of managerial operations that the manufacturing efficiency of any system cannot reach absolute optimization. In addition, it is more reasonable to search for satisfactory efficiency, which is suitable for industry system. The DEA model provides the solution for working out satisfactory efficiency and pointing out developmental orientation as systemic optimizing objective [59]. At present, the $C^{2} R$ model and $C^{2} G S^{2}$ model of the DEA method have been widely applied in many fields. Mathematical formulas of two models have been described in many monographs and academic papers [60], $C^{2} R$ model and $C^{2} G S^{2}$ model can be described as Equations (4) and (5).

The obvious distinction between the $C^{2} R$ model and $C^{2} G S^{2}$ model is the different resistance of model optimum solution $\lambda_{j}$, and the $C^{2} G S^{2}$ model can't meet cone characteristic (which means that $k$ times resource input can't bring out $k$ times output) [61]. In the economic system, the construction of evaluation indexes system is complicated, some indexes meet core characteristics while others do not, partial important influencing factors would inevitably been given up based on the single DEA model. Therefore, the construction of the mixed DEA model, which can contain two categories of measurement indexes for describing an economic system objectively, is established [62]. Furthermore, if excessive decision units' DEA efficiency coefficients are equal to 1.000, decision units cannot be distinguished. To avoid this situation, self-limited condition of decision units in mixed DEA model is wiped off, and then super efficiency mixed DEA model can be constructed and described as Equation (6). 


$$
\begin{aligned}
& \begin{array}{c}
\left(D_{C^{2} R}\right)\left\{\begin{array}{c}
\min \theta_{0} \\
s t . \\
\sum_{j=1}^{n} X_{j} \times \lambda_{j}+S^{-}=\theta_{0} \times X_{j} \\
\sum_{j=1}^{n} Y_{j} \times \lambda_{j}-S^{+}=Y_{j} \\
\lambda_{j} \geq 0, j=1,2, \cdots, n \\
S^{+} \geq 0, S^{-} \geq 0 \\
\min \theta_{0} \\
s t .
\end{array}\right. \\
\left\{\begin{array}{c}
\left.n \quad D_{C^{2} G S^{2}}\right)\left\{\begin{array}{c}
\sum_{j=1}^{n} X_{j} \times \lambda_{j}+S^{-}=\theta_{0} \times X_{j} \\
\sum_{j=1}^{n} Y_{j} \times \lambda_{j}-S^{+}=Y_{j}
\end{array}\right. \\
\sum_{j=1}^{n} \lambda_{j}=1, \lambda_{j} \geq 0, j=1,2, \cdots, n \\
S^{+} \geq 0, S^{-} \geq 0
\end{array}\right.
\end{array} \\
& \left(D_{\text {Combine }}\right)\left\{\begin{array}{c}
\min { }^{\theta} \\
\text { st. }
\end{array}\right.
\end{aligned}
$$

In Equation (6), $X_{j}=\left[x_{i j}\right]_{m \times n}(i=1,2, \ldots, m)$ represents $m$ input indexes of No. $j(j \in J)$ decision unit. In addition, $U_{j}=\left[u_{i j}\right]_{k \times n}(i=1,2, \ldots, k), Y_{j}=\left[y_{i j}\right]_{s \times n}(i=1,2, \ldots, s)$ and $V_{j}=\left[v_{i j}\right]_{l \times n}(i=1,2, \ldots, l) . X_{j}$ and $Y_{j}$ represent input and output indexes which meet cone characteristic, $U_{j}$ and $V_{j}$ represent input and output indexes which cannot meet cone characteristic [63]. $S^{-}, S^{+}, R^{-}$and $R^{+}$represent slack variables, $\lambda_{j}$ represents optimum solution of model, $\Phi$ represents coefficient. If $X_{j}$ raises $\Phi$ times, $Y_{j}$ raises $\Phi$ times correspondingly. In general, when the output equals $y$, if corresponding $x$ does not decrease, this kind of 
manufacturing process can be confirmed as technical validity. As for the input scale $X_{0}$, if the input is smaller than $X_{0}$, system represents incremental status of scale benefit, if input is larger than $X_{0}$, system represents decrement status of scale benefit, this kind of $\operatorname{DMU}_{j}\left(X_{0}, f\left(X_{0}\right)\right)$ can be confirmed as scale validity. $C^{2} R$ model which reflects unchangeable scale benefit is suitable to measure scale validity of decision units, $C^{2} G S^{2}$ model which reflects changeable scale benefit is suitable to measure technical validity [64]. With the application of super efficiency mixed DEA model, valid decision units can represent both technical validity and scale validity. According to the scholar $\mathrm{Wu}$, manufacturing possible group of $D_{\text {Combine }}$ model can be described as Equation (7).

$$
\left\{(X, U, Y, Z) \mid \begin{array}{c}
X \geq \sum_{j \in J} X_{j} \times \lambda_{j} \\
U \geq \frac{1}{\Phi} \times \sum_{j \in J} U_{j} \times \lambda_{j} \\
Y \leq \sum_{j \in J} Y_{j} \times \lambda_{j} \\
V \leq \frac{1}{\Phi} \times \sum_{j \in J} V_{j} \times \lambda_{j} \\
\Phi \geq 0, \sum_{j \in J} \lambda_{j}=\Phi \\
\lambda_{j} \geq 0, j \in J
\end{array}\right\}
$$

\section{Results}

\subsection{Analytical Units and Statistical Data for Empirical Research}

In the economic system of China, the industry system contributes to more than thirty-five percent of the gross output value and thirty percent of the total employment. The values of two above-mentioned indexes have been increasing in recent several years. However, the extensive growth mode of the industry system has resulted in serious resource waste and environmental pollution. It reflects the unbalance of the industrial structure. In addition, that industrial growth features "high inputs, heavy pollution and serious damage" are obvious. It is highly essential to improve the sustainable developmental capability and deal with the sharp conflict between industrial operation and ecological environmental capacity. Importance should be attached to the quality of industrial growth. It is a practical path to strengthen the evolutionary capability from Hierarchy II to Hierarchy III of industrial ecological niche so as to reduce the negative affect of the industry system on ecological environment and improve industrial operational efficiency. To sum up, the industry system in China is a suitable analytical object and the status of industrial operation of different years can be chosen as analytical units with the data envelopment analysis (DEA) method. From the view of input and output, statistical data from the 1993 to 2012 China annual book serves as empirical data for analyzing the economic connotation and the evolutionary discipline with the application of a super efficiency mixed DEA model. 


\subsection{Calculating Procedure and Measurement Values}

An empirical analysis is carried out based on a super efficiency mixed DEA model and statistical data of the industry system from 1993 to 2012, With the application of the engineering calculating software Matlab 7.01, the procedure coefficients (coefficient $\Phi$ ) and the measurement values (initial values of measurement $\theta_{0}$ and standard values of measurement $\left.\theta^{*}\right)$ can be calculated and shown as in Table 3 .

Table 3. Procedural coefficient and measurement values of industrial operation efficiency.

\begin{tabular}{cccc}
\hline Analytical Units & $\begin{array}{c}\text { Procedural Coefficient } \\
\text { of DEA Model } \boldsymbol{\Phi}\end{array}$ & $\begin{array}{c}\text { Initial Values of } \\
\text { Measurement } \boldsymbol{\theta}_{\mathbf{0}}\end{array}$ & $\begin{array}{c}\text { Standard Values of } \\
\text { Measurement } \boldsymbol{\theta}^{*}\end{array}$ \\
\hline 1993 & 0.6173 & 0.7804 & 0.4353 \\
1994 & 0.3647 & 0.7645 & 0.4265 \\
1995 & 0.5037 & 0.7340 & 0.4095 \\
1996 & 0.5700 & 0.7000 & 0.3905 \\
1997 & 0.4396 & 0.6679 & 0.3726 \\
1998 & 0.4454 & 0.6138 & 0.3424 \\
1999 & 0.4070 & 0.6821 & 0.3805 \\
2000 & 0.4696 & 0.8010 & 0.4468 \\
2001 & 0.4783 & 0.8584 & 0.4789 \\
2002 & 0.5405 & 1.1230 & 0.6264 \\
2003 & 0.5593 & 0.9811 & 0.5473 \\
2004 & 0.5035 & 0.9128 & 0.5092 \\
2005 & 0.7240 & 0.9389 & 0.5237 \\
2006 & 0.5218 & 1.0653 & 0.5943 \\
2007 & 0.6389 & 1.1144 & 0.6217 \\
2008 & 0.8479 & 1.5379 & 0.8579 \\
2009 & 0.8919 & 1.5549 & 0.8674 \\
2010 & 0.8784 & 1.5857 & 0.8846 \\
2011 & 0.5805 & 1.6271 & 0.9077 \\
2012 & 0.2002 & 1.7926 & 1.0000 \\
\hline
\end{tabular}

\subsection{Optimization Values of Redundancy Cost}

Based on unchanged output values of decision units, the serious redundancy values represent the percentage of human, capital, energy and environment costs. These redundancy values can be calculated and should be decreased. According to the Equations (6) and (7), if the variable set of decision unit can

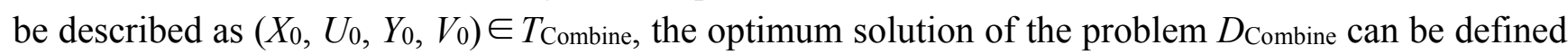
as the following parameters and coefficients $\lambda_{j}^{0}(j \in J), \theta_{0}, \Phi_{0}, S^{0-}, R^{0-}, S^{0+}, S^{0+}$, inspection of the corresponding simplex tableau $(\pi)$ are all nonnegative numbers. If $R^{0-}=0$ and $R^{0+}=0,\left(X_{0}, U_{0}, Y_{0}, V_{0}\right)$ is valid in the DEA model ( $\left.D_{\text {Combine }}\right)$ comparing with original $n$ decision units.

According to the Equation (8) and Table 3, redundancy data can be calculated and shown as Table 4. Based on unchanged output values of decision units, the relative efficiency results can be defined as the standard rulers, and the serious redundancy values of assess capital, human capital, environment capital and energy capital can be calculated. These redundancy values will be applied in giving birth to adjustment strategies to improve serious environmental pollution and resources waste. The standard values of 
measurement $\theta^{*}$ in Table 3 reflect the relative evolutional status of industrial ecological niches of different analytical years. The higher the values of measurement $\theta^{*}$ are, the better the evolutional status is. However, the value of year 2012 that equals to 1.0000 still does not match the first-best evolutional statuses. It represents a relative validity and redundancy values of different input indexes still occur comparing with the more excellent comparative criterions. The repeating calculation of redundancy values can be carried out based on gradual and more excellent comparative criterions. It is surely beneficial for providing analytical data to improve the evolutional status from low-level to high-level industrial ecological niches.

$$
\left\{\begin{array}{c}
\hat{X}_{0}=\sum_{j \in J} X_{j} \times \lambda_{j}^{0} / \Phi_{0}=\left(\theta_{0} \times X_{0}-S^{0-}\right) / \Phi_{0} \\
\widehat{U}_{0}=\sum_{j \in J} U_{j} \times \lambda_{j}^{0} / \Phi_{0}=U_{0}-R^{0-} / \Phi_{0} \\
\hat{Y}_{0}=\sum_{j \in J} Y_{j} \times \lambda_{j}^{0} / \Phi_{0}=\left(Y_{0}+S^{0+}\right) / \Phi_{0} \\
\widehat{V}_{0}=\sum_{j \in J} V_{j} \times \lambda_{j}^{0} / \Phi_{0}=V_{0}+R^{0+} / \Phi_{0}
\end{array}\right.
$$

\section{Discussion and Conclusions}

\subsection{Discussion of Results}

According to the measurement values shown in Table 3, the industrial operational efficiency gradually declined from 1993 to 1998 due to the extensive growth mode and corresponding serious damage to the ecological environment. Devastating floods occurred in 1998. From then on, the national government paid great attention to the restoration of the ecological environment through many environmental protection policies such as reforestation of "the cultivated land, close hillsides to facilitate afforestation and seeding projects". Correspondingly, the ecological environment was improved to a certain extent and the measurement values reflected a rising trend from 1999 to 2002 . However, single environmental protection policies could only make limited contributions if the present extensive growth mode of industry system remained unchanged, and the industry system resulted in even more serious pollution with the rapid increment of production values. It can be observed that measurement values reflect significant decline in 2003 and 2004. From then on, the central government gradually recognized the importance of improving industrial operational efficiency in order to address the pollution and restore ecological environmental functions. With the guidance of Recycling Theory, the central government made great efforts to transform the operational mode of the industry system from the extensive growth mode to the intensive growth mode. Necessary measures such as the optimization of industrial structure, the application of clean technology, the utilization of recycled materials and the strict limitation of different categories of industrial pollutants discharge were taken to improve the industrial operational efficiency for guaranteeing the achievement of sustainable developmental objectives in China. It can be concluded that there is a continuous and significant increment of measurement values from t 2005 to 2012, and this trend indicates the improvement of sustainable development capability. 
Table 4. Optimization proportion of redundancy values based on unchanged output values.

\begin{tabular}{cccccccc}
\hline $\begin{array}{c}\text { Analytical } \\
\text { Units }\end{array}$ & $\begin{array}{c}\text { Redundant } \\
\text { Percent of } \\
\text { Index } \boldsymbol{X}_{\mathbf{1}}\end{array}$ & $\begin{array}{c}\text { Redundant } \\
\text { Percent of } \\
\text { Index } \boldsymbol{X}_{\mathbf{2}}\end{array}$ & $\begin{array}{c}\text { Redundant } \\
\text { Percent of } \\
\text { Index } \boldsymbol{X}_{\mathbf{3}}\end{array}$ & $\begin{array}{c}\text { Redundant } \\
\text { Percent of } \\
\text { Index } \boldsymbol{X}_{\mathbf{4}}\end{array}$ & $\begin{array}{c}\text { Redundant } \\
\text { Percent of } \\
\text { Index } \boldsymbol{X}_{\mathbf{5}}\end{array}$ & $\begin{array}{c}\text { Redundant } \\
\text { Percent of } \\
\text { Index } \boldsymbol{X}_{\mathbf{6}}\end{array}$ & $\begin{array}{c}\text { Redundant } \\
\text { Percent of } \\
\text { Index } \boldsymbol{X}_{\mathbf{7}}\end{array}$ \\
\hline 1993 & 19.604 & 19.970 & 15.929 & 16.298 & 14.225 & 15.170 & 15.568 \\
\hline 1994 & 16.968 & 17.597 & 15.289 & 17.575 & 16.407 & 16.369 & 16.220 \\
\hline 1995 & 19.622 & 17.047 & 16.497 & 18.894 & 17.495 & 17.043 & 16.696 \\
\hline 1996 & 18.782 & 21.764 & 16.941 & 19.334 & 18.733 & 17.983 & 17.553 \\
\hline 1997 & 21.052 & 19.418 & 15.878 & 20.855 & 19.760 & 18.394 & 18.558 \\
\hline 1998 & 21.352 & 22.037 & 18.739 & 21.087 & 19.858 & 19.423 & 22.136 \\
\hline 1999 & 23.544 & 22.508 & 17.345 & 20.679 & 20.202 & 16.696 & 21.008 \\
\hline 2000 & 21.405 & 19.953 & 15.892 & 19.554 & 14.943 & 14.039 & 17.512 \\
\hline 2001 & 18.614 & 17.516 & 15.598 & 17.820 & 13.660 & 14.069 & 15.815 \\
\hline 2002 & 12.202 & 14.772 & 14.600 & 15.674 & 11.210 & 12.413 & 13.415 \\
\hline 2003 & 15.614 & 16.102 & 16.645 & 17.463 & 13.186 & 13.493 & 14.368 \\
\hline 2004 & 17.020 & 17.083 & 13.912 & 17.781 & 15.353 & 14.908 & 15.327 \\
\hline 2005 & 16.214 & 19.926 & 16.094 & 16.517 & 14.891 & 14.086 & 16.682 \\
\hline 2006 & 15.828 & 16.218 & 18.654 & 15.832 & 14.111 & 13.501 & 12.827 \\
\hline 2007 & 13.742 & 15.357 & 12.936 & 15.060 & 10.976 & 12.521 & 12.642 \\
\hline 2008 & 14.348 & 15.146 & 15.745 & 13.773 & 9.673 & 12.118 & 13.391 \\
\hline 2009 & 11.052 & 12.219 & 11.004 & 11.059 & 10.887 & 10.966 & 10.849 \\
\hline 2010 & 8.528 & 9.066 & 7.845 & 5.965 & 8.640 & 8.680 & 6.745 \\
\hline 2011 & 8.017 & 7.478 & 6.559 & 5.237 & 7.083 & 8.142 & 5.900 \\
\hline 2012 & 0.007 & 0.014 & 0.006 & 0.012 & 0.008 & 0.013 & 0.009 \\
\hline
\end{tabular}

According to Table 4, it can be obviously found out that there are four significant developmental trends which can be described as M-Curve shape. The first trend reflects a continuous increment from 1993 to 1998; the second trend reflects a decline from 1999 to 2002; the third trend reflects a temporary increment from 2003 to 2004 and the fourth trend reflects a successive decline from 2005 to 2012 in the redundancy values of environment and energy costs caused by industry operation. The following input indexes such as annual exhaust emission of the industry system $\left(X_{4}\right)$, annual unstandardized waste water of the industry system $\left(X_{5}\right)$, annual unutilized solid waste of the industry system $\left(X_{6}\right)$ and annual energy consumption of the industry system $\left(X_{7}\right)$ are especially significant. As for further analysis, the following reasons may account for the above-mentioned trend. Firstly, the central government put more and more emphasis on ecological environmental functions of forest; a series of environmental protection policies were put forward, such as reforestation of the cultivated land, close hillsides to facilitate afforestation and seeding projects. These policies aimed at restoring the ecological functions of the forest. Secondly, the carbon emissions trading market was established to compensate for the preservation of ecological benefits. It provided a practical commercial mode for institutions specialized in ecological service. More importantly, the central government made great efforts to optimize the industrial organization and the industrial structure, and plenty of clean techniques were applied in the manufacturing process. Restrictive limitations of different categories of pollutants discharge were made to achieve industry ecologicalization. With the guidance of Recycling Theory, the industrial operational efficiency has been improved and the growth mode has been transformed from the extensive one to the intensive one. 
The industrial ecological niche is reflecting evolutionary trend from hierarchy II to hierarchy III for achieving coordinative sustainable development between the industrial operation and the ecological environmental capacity.

\subsection{Conclusions}

Based on Ecological Niche Theory and the analysis framework of an economic growth model with environmental elements, the connotation of the industrial ecological niche is defined, the evolutionary sequence of different hierarchies of industrial ecological niches are categorized and the dimension structure of the evolutionary capability is analyzed. The measurement of the evolutionary capability of the transition from Hierarchy II to Hierarchy III is carried out through calculating values of industrial operational efficiency to provide administrative data for strategic adjustments. As for the empirical analytical method, multiple input and out indexes which contains both meeting cone characteristic indexes or not should be considered, and scientific and accurate values can be calculated with the application of a super efficiency mixed DEA model in the evaluation of relative efficiency validity of multiple decision units. Sequential order of the decision unit's relative efficiency can be acquired so as to reflect operational status of industry system. From the view of input and output, statistical data from the 1993 to 2012 China annual book can be collected as empirical data to carry out further analysis so as to discover economic connotations and evolutional disciplines of industrial operational efficiency. According to the procedural coefficients and measurement values with the application of a super efficiency mixed DEA model, redundancy values of different input indexes, which reflect the costs of human activity, capital energy and the environment can be calculated to provide necessary administrative information. These analytical data are surely valuable to constitute practical measures. In recent years, plenty of environmental protection policies such as reforestation of the cultivated land close to hillsides to facilitate afforestation and seeding projects have been implemented by the national government and regional governments for the restoration of ecological environment.

According to Figures 6 and 7 and Table 5, some indexes such as volumes of waste water, industrial emission and solid waste per ten thousands RMB GDP have significantly decreased, and the utilization efficiency of energy and water have gradually increased from 1993 to 2012 [65]. In Figure 6, the $X$ axis represents analytical year (every graduation represents different analytical year from 1993 to 2012), the $Y$ axis represents the volume of water consumption (every graduation represents twenty tons per thousand RMB GDP, the maximum is one hundred and eighty tons per thousand RMB GDP) and the dots represent volume of water consumptions of different analytical years (tons per thousand RMB GDP). In Figure 7, the $X$ axis represents the analytical year (every graduation represents different analytical year from 1993 to 2012), the $Y$ axis represents the volume of energy consumption (every graduation represents twenty tons per million of RMB GDP, the maximum is two hundreds of tons per million of RMB GDP) and the dots represent the volume of energy consumptions of different analytical years (tons per million of RMB GDP). To sum up, the governments have made great efforts to transform the operational mode of industry system from the extensive growth mode to the intensive growth mode. Many necessary environmental policies such as the optimization of industrial structure, the application of clean technology, the utilization of recycled materials and the strict limitation of different categories 
of industrial pollutants discharge have been taken to improve industrial operational efficiency for promoting sustainable development capability.

Figure 6. Volume of water consumption per thousand of RMB GDP from 1993 to 2012.

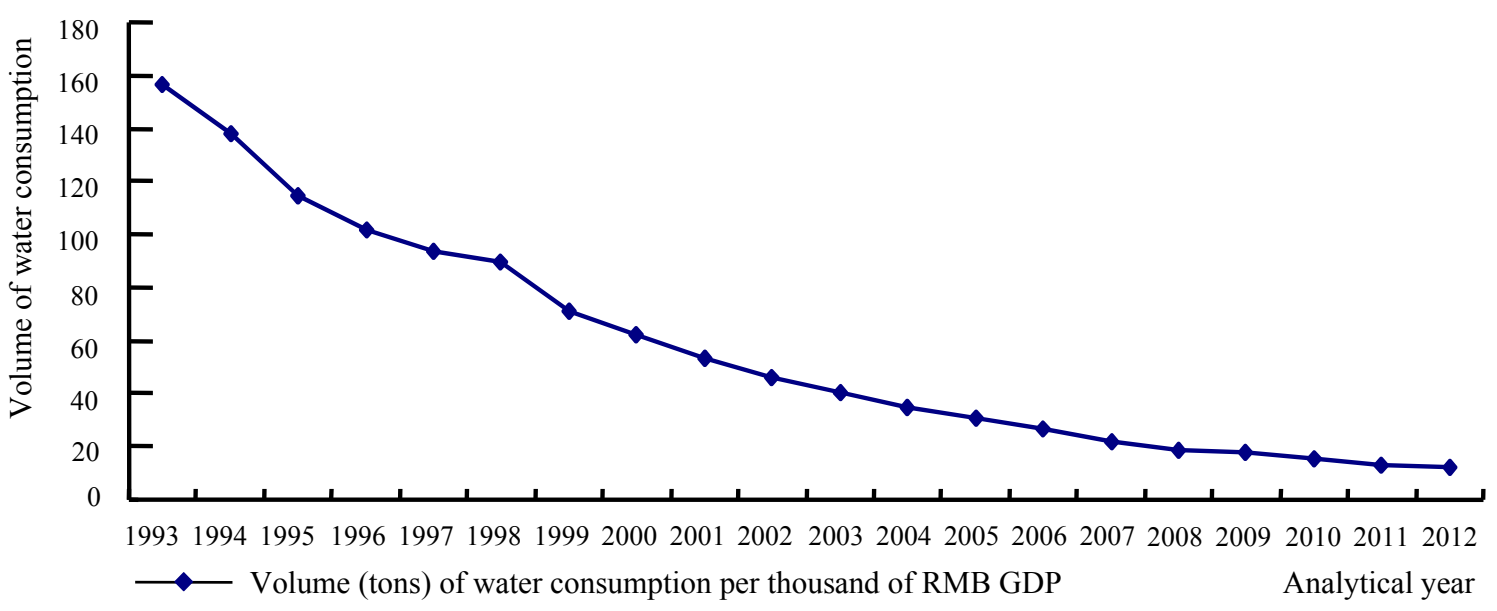

Figure 7. Volume of energy consumption per million of RMB GDP from 1993 to 2012.

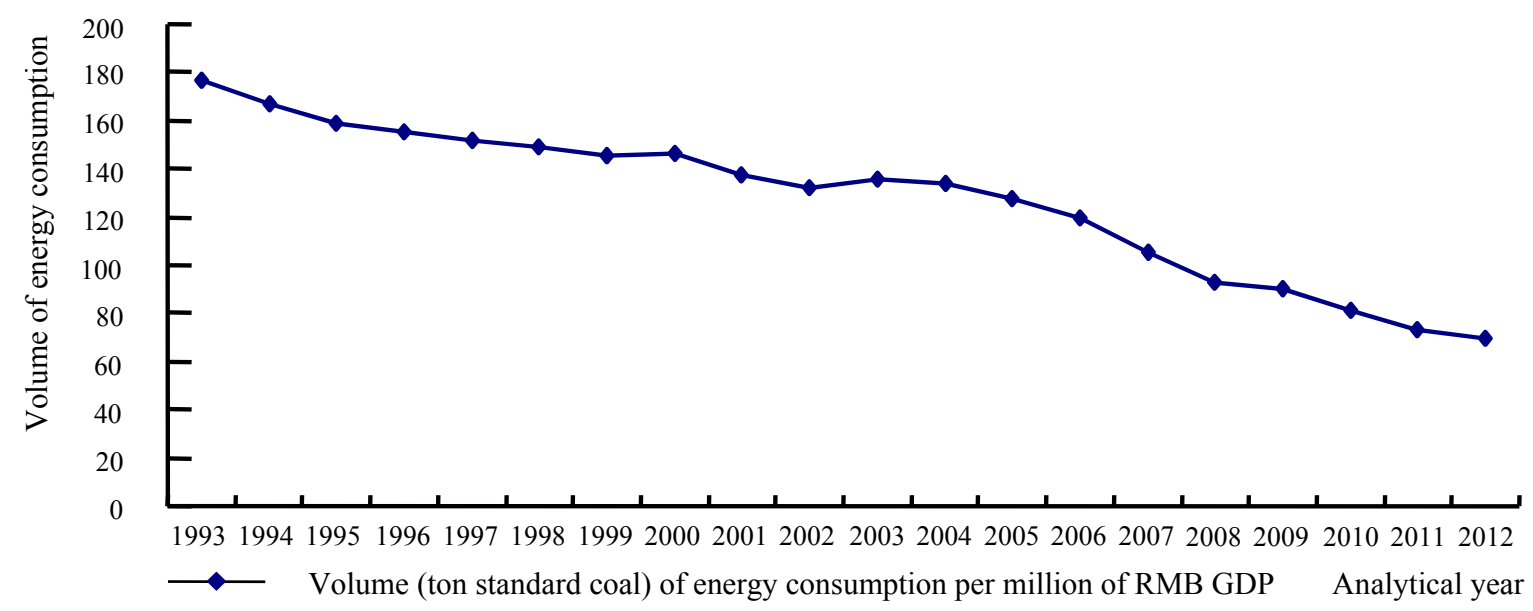

Table 5. Optimization proportion of redundancy values based on unchanged output values.

\begin{tabular}{cccc}
\hline Year & $\begin{array}{c}\text { Volume of Waste Water (Cubic } \\
\text { Meters per Thousand RMB) }\end{array}$ & $\begin{array}{c}\text { Emissions of Waste Gas } \\
\text { (Tons per Million RMB) }\end{array}$ & $\begin{array}{c}\text { Emissions of Solid Waste } \\
\text { (Tons per Million RMB) }\end{array}$ \\
\hline 2012 & 1.2996 & 0.4423 & 0.6148 \\
2011 & 1.3933 & 0.4740 & 0.7359 \\
2010 & 1.5373 & 0.5448 & 0.8723 \\
2009 & 1.7280 & 0.6512 & 1.3230 \\
2008 & 1.8204 & 0.7433 & 1.6316 \\
2007 & 2.0949 & 0.9330 & 2.1809 \\
2006 & 2.3784 & 1.2004 & 3.2832 \\
2005 & 2.8361 & 1.3804 & 4.0732 \\
2004 & 3.0174 & 1.4199 & 4.6514 \\
2003 & 3.4391 & 1.7830 & 6.3537 \\
2002 & 3.8742 & 2.0155 & 7.8626 \\
\hline
\end{tabular}


Table 5. Cont.

\begin{tabular}{cccc}
\hline Year & $\begin{array}{c}\text { Volume of Waste Water (Cubic } \\
\text { Meters per Thousand RMB) }\end{array}$ & $\begin{array}{c}\text { Emissions of Waste Gas } \\
\text { (Tons per Million RMB) }\end{array}$ & $\begin{array}{c}\text { Emissions of Solid Waste } \\
\text { (Tons per Million RMB) }\end{array}$ \\
\hline 2001 & 4.3367 & 2.3224 & 9.4715 \\
2000 & 4.8693 & 2.6801 & 11.4807 \\
1999 & 5.4674 & 3.1330 & 13.9344 \\
1998 & 6.4496 & 3.8745 & 15.1948 \\
1997 & 6.7916 & 4.0831 & 16.3132 \\
1996 & 7.3714 & 4.3241 & 20.0419 \\
1995 & 8.5230 & 4.9634 & 26.2713 \\
1994 & 9.5434 & 5.8828 & 34.2238 \\
1993 & 10.6231 & 6.7745 & 50.6609 \\
\hline
\end{tabular}

\subsection{Shortcomings and Further Improvement}

Empirical research was carried out based on statistical data from China. The single data source is positive to verify the scientificity of theoretical analytical framework. The statistical data from other, more different regions should be collected to verify rationality and practicality of indexes and model on which can be applied in measuring the damage degree of environmental capacity caused by industrial operation. Based on longitudinal and horizontal statistical data from different regions, more valuable adjustment strategies can be provided.

With the application of a super efficiency mixed DEA model, redundancy values of different input indexes which reflect the costs of human, capital, energy and environment can be calculated. However, these values can only reflect the present status. The limit range of different input and output indexes should be calculated so as to precisely measure the contributions of different input indexes and output indexes on manufacturing efficiency, technical efficiency and scale efficiency through decomposition model and derivative model in the further research.

Simple liner evolutional relations among different industrial ecological niches of Hierarchy I (which reflects extensive economic growth with the industry value centered), Hierarchy II (which reflects transitive economic growth with the consideration of ecology), Hierarchy III (which reflects intensive growth with the guidance of a low carbon economy concept) and Hierarchy IV (which reflects sustainable growth with the guidance of circular economy theory) are considered. Non-liner relations among sub-ecological niches would be analyzed to explain the effect of the industrial ecological niche on the sustainable development capability in further researches.

\section{Acknowledgments}

This research is financially supported by National Natural Science Fund Project (No.71002048), Ministry of Education Doctoral Specialty Foundation Project (No. 20102304120017), National Social Science Fund (No.11CGL040), The National Soft Science Research Program (2013GXS4B070), Heilongjiang Natural Science Fund Project of (No.G201311), MOE Project of Humanities and Social Sciences (No.09YJC630048) and the Central Universities Basic Science Fund Project of Harbin Engineering University (No.HEUCF120901). 


\section{Author Contributions}

The authors contributed equally to this work. All authors have read and approved final manuscript.

\section{Conflicts of Interest}

The authors declare no conflict of interest.

\section{References}

1. Zhang, K.T.; Wen, Z.G. Review and challenges of policies of environmental protection and sustainable development in China. J. Environ. Manag. 2008, 88, 1249-1261.

2. Perles, R.; Vías, M.B. Vulnerability of human environment to risk: Case of ground-water contamination risk. Environ. Int. 2009, 35, 325-335.

3. Veena, S.; Karen, C.S. The impact of urbanization on water vulnerability: A coupled human-environment system approach for Chennai, India. Glob. Environ. Chang. 2013, 66, 229-239.

4. Li, M.N.; Zhang, L.L. Haze in China: Current and future challenges. Environ. Pollut. 2014, 189, $85-86$.

5. Grossman, G.M.; Krueger, A.B. Environmental impacts of a North American Free Trade Agreement. In National Bureau of Economic Research Working Paper; MIT Press: Cambridge, MA, USA, 1991; Volume 3914, pp. 1-39.

6. Kuznets, S. Economic growth and income inequality. Am. Econ. Rev. 1955, 45, 12-35.

7. Grossman, G.M.; Alan, K. Economic growth and the environment. Q. J. Econ. 1995, 110, 13-37.

8. Gibson, R.B.; Walker, A. Assessing trade: An evaluation of the commission for environmental cooperation's analytic framework for assessing the environmental effects of North American Free Trade Agreement. Environ. Impact Assess. Rev. 2001, 21, 449-468.

9. Hu, D.; Xu, K.P.; Yang, J.X. Economic development and environmental quality: Progress on the Environmental Kuznets Curve. Acta Ecol. Sin. 2004, 24, 1259-1266.

10. Saboori, B.; Sulaiman, J. Environmental degradation, economic growth and energy consumption: Evidence of the environmental Kuznets Curve in Malaysia. Energy Policy 2013, 60, 892-905.

11. Wang, Y.; Kang, L.Y.; Wu, X.Q.; Xiao, Y. Estimating the environmental Kuznets curve for ecological footprint at the global level: A spatial econometric approach. Ecol. Indic. 2013, 34, 15-21.

12. Ana, J.; López, M.; Rigoberto, P.; Blanca, M. Environmental costs and renewable energy: Re-visiting the Environmental Kuznets Curve. J. Environ. Manag. 2014, 145, 368-373.

13. Ling, K.; Wang, H.C.; Liu, T. The Statistical Research on the relationship between urban economic development and environmental pollution: The case of Nanjing city. Stat. Res. 2001, 11, 46-57.

14. Liu, Y.B.; Li, R.D. Exploring on environmental Kuznets characteristics of wastewater, waste gas and solid wastes and their causes in Wuhan City. Urban Environ. Urban Ecol. 2003, 16, 44-45.

15. Brajer, V.; Mead, R.W.; Xiao, F. Searching for an environmental Kuznets Curve in China's air pollution. China Econ. Rev. 2011, 22, 383-397.

16. Jayanthakumaran, K.; Ying, L. Openness and the environmental Kuznets Curve: Evidence from China. Econ. Model. 2012, 29, 566-576. 
17. Steven, P.C.; Stephen, F.H. The transition from dirty to clean industries: Optimal fiscal policy and the environmental Kuznets curve. J. Environ. Econ. Manag. 2004, 48, 1050-1077.

18. Yang, W.J. Measuring eco-efficiency with data envelopment analysis: An example of provincial industry in China. Sci. Econ. Soc. 2009, 29, 56-67.

19. Duan, X.M. Relationship between economic growth and environmental pollution in Zhejiang: An empirical analysis based on VAR Model. J. Chongqing Jiaotong Univ. 2012, 12, 52-61.

20. Majid, H.; Syed, M.H.Z.; Riffat, N.M.; Benktesh, D.S. Greenhouse gas emissions from production chain of a cigarette manufacturing industry in Pakistan. Environ. Res. 2014, 134, 81-90.

21. Romer, P.M. Increasing Returns and Long Run Growth. J. Polit. Econ. 1986, 95, 1002-1037.

22. Yin, J. Introduction of learning by doing and endogenous human capital to endogenous growth model. World Econ. Papers 2003, 47, 30-37.

23. He, J.; Chen, H.P.; Bi, G.B. An endogenous growth model based on product-adding innovations and human capital. J. Quant. Tech. Econ. 2006, 23, 127-136.

24. Zhang, T. Demand analysis in sustainable economic increase. J. Quant. Tech. Econ. 2001, 18, 43-49.

25. Wang, H.; Yan, Z.G.; Li, H. Progress of environmental management and risk assessment of industrial chemicals in China. Environ. Pollut. 2012, 165, 174-181.

26. Zhao, X.L.; Zhang, S.F.; Fan, C.Y. Environmental externality and inequality in China: Current Status and future choices. Environ. Pollut. 2014, 190, 176-179.

27. Gao, X.L.; Zhou, F.X.; Chen, C.T.A. Pollution status of the Bohai Sea: An overview of the environmental quality assessment related trace metals. Environ. Int. 2014, 62, 12-30.

28. Yu, B.T.; Yu, B. Research on CRE efficiency in an industrial system based on the endogenous theory of environmental elements. J. Harbin Eng. Univ. 2010, 31, 1549-1558.

29. Yang, S.L.; Li, T.F. Agility evaluation of mass customization product manufacturing. J. Mater. Proc. Technol. 2002, 129, 640-644.

30. Xue, X.F.; Tan, Z. The research on knowledge innovation mechanism and knowledge niche of virtual enterprise. J. Intell. 2008, 27, 73-79.

31. He, J.F. Technological competence evolution model based on niche theory. Ind. Eng. J. 2008, $11,32-41$.

32. Sun, B. A study on technology niche's status from the perspective of network relationship. Stud. Sci. 2013, 42, 518-529.

33. Ji, Q.Y.; Lin, J. The evaluation method for core competence of colleges and universities based on the niche theory. China Soft Sci. 2006, 31, 145-155.

34. Xu, F.; Li, J.H. Study of principle and model of enterprise niche. China Soft Sci. 2005, 30, 130-141.

35. Yan, A.; Da, Q.L. A model of enterprise evolution based on niche construction. East China Econ. Manag. 2009, 23, 293-316.

36. Laland, K.N.; Odling-Smee, F.J.; Feldman, M.W. Evolutionary consequences of niche construction: A theoretical investigation using two locus theory. J. Evol. Biol. 1996, 9, 293-316.

37. Xiao, Y.; Mao, X.Q. Urban niche theory and its application. China Pollut. Resourc. Environ. 2008, $18,41-45$.

38. Topuz, E.; Talinli, I.; Aydin, E. Integration of environmental and human health risk assessment for industries using hazardous materials: A quantitative multi criteria approach for environmental decision makers. Environ. Int. 2011, 37, 393-403. 
39. Gibbs, D.; Deutz, P. Reflections on implementing industrial ecology through eco-industrial park development. J. Clean. Prod. 2007, 15, 1683-1695.

40. Du, Y.W.; Zhang, P.; Ren, J. Analysis of the energy efficiency in the large enterprises from an industrial ecology perspective: Case study from BaoGang group. Energy Procedia 2011, 5, 1237-1242.

41. Despeisse, M.; Ball, P.D.; Evans, S.; Levers, A. Industrial ecology at factory level-a conceptual model. J. Clean. Prod. 2012, 31, 30-39.

42. Alessandro, D.; Tiziano, B.; Andrea C. Development and application of an innovative expert decision support system to manage sediments and to assess environmental risk in freshwater ecosystems. Environ. Int. 2013, 60, 171-182.

43. Shaleen, S.; Amit, K. Industrial estate planning and management in Indiavative expert decision support industrial ecology. J. Environ. Manag. 2002, 66, 19-29.

44. Han, D.F.; Xu, J.H.; Su, F.L. Review on Kuznets Curve. Environ. Sustain. Dev. 2006, 31, 123-129.

45. Shafik, N.; Bandyopadhyay, S. Economic growth and environmental quality: Time series and cross-country evidence. In Background Paper for World Development Report 1992, 1st ed.; World Bank: Washington, DC, USA, 1992; pp. 1-50.

46. Pan, J.H. Economic Analysis of Sustainable Development, 1st ed.; China Renmin University Press: Beijing, China, 1997; pp. 177-193.

47. Li, Z.; Bao, X.B. Estimation of Kuznets Curve of China's Environment. Sci. Technol. Rev. 2002, $23,57-87$.

48. Tsuzuki, Y. An index directly indicates land-based pollutant load contributions of domestic wastewater to the water pollution and its application. Sci. Total Environ. 2006, 370, 425-440.

49. Sang, H.K.; Yoon, S.G.; Song, H.C.; Park, S.W. Economic and environmental optimization of a multi-site utility network for an industrial complex. J. Environ. Manag. 2010, 91, 690-705.

50. Wu, Y.P.; Dong, S.C.; Song, J.F. Modeling economic growth and environmental degradation of Beijing. Geogr. Res. 2002, 21, 241-253.

51. Yang, K.; Ye, M.; Xu, Q.X. Environmental Kuznets characteristics of municipal solid waste growth in Shanghai city. Geogr. Res. 2003, 22, 60-67.

52. Cai, Z.B.; Li, Z.Y. The research on the Environmental Kuznets Curve of Jiangsu province based on the panel data model. China Dev. 2012, 12, 6-17.

53. Zhuang, D.C.; Ye, H.; Zhang, H.X. Relationship of economic development and water environmental pollution in Guangzhou. Econ. Geogr. 2013, 33, 38-41.

54. Fang, Y.P.; Raymond, P.C.; Qin, R. Industrial sustainability in China: Practice and prospects for eco-industrial development. J. Environ. Manag. 2007, 83, 315-328.

55. Sabadie, J.A. Technological innovation, human capital and social change for sustainability. Lessons learnt from the Industrial Technologies Theme of the EU's Research Framework Programme. Sci. Total Environ. 2014, 481, 668-673.

56. Yu, B.T.; Yu, B. Research on CRE efficiency of industrial system based on improvement of ecological niche. Oper. Res. Manag. Sci. 2010, 19, 161-169.

57. Wu, W.J. Analysis and Application of Data Envelopment Analysis Model, 1st ed.; China Statistics Press: Beijing, China, 2002; pp. 114-229.

58. Wei, Q.L. Data Envelopment Analysis, 2nd ed.; Science Press: Beijing, China, 2004; pp. 209-217. 
59. Hirofumi, F.; Mirdehghan, S.M. Identifying the efficiency status in network DEA. Eur. J. Oper. Res. 2012, 220, 85-92.

60. Samoilenko, S.; Osei-Bryson, K.M. Using data envelopment analysis (DEA) for monitoring efficiency-based performance of productivity- driven organizations: Design and implementation of a decision support system. Omega 2013, 41, 131-142.

61. Andre, F.J.; Herrero, I. A modified DEA model to estimate the importance of objectives with an application to agricultural economics. Omega 2010, 38, 371-382.

62. Wu, J.; An, Q.X.; Shujahat, A.; Lian, L. DEA based resource allocation considering environmental factors. Math. Comput. Model. 2013, 58, 1128-1137.

63. Fu, Y.W.; Yin, H. Evaluation on relative efficiency validity of medicine industry companies based on mixed DEA model. Chin. J. Manag. Sci. 2006, 14, 91-102.

64. Yin, H. Analysis and evaluation of relative efficiency of industrial system based on super-efficiency mixed DEA Model. Oper. Res. Manag. Sci. 2008, 17, 143-152.

65. Yin, H.; Li, B.Z.; Guo, T.; Zhu J.X. Measurement Method and Empirical Research on Systemic Vulnerability of Environmental Sustainable Development Capability. Polish J. Environ. Stud. 2014, $23,243-253$.

(C) 2014 by the authors; licensee MDPI, Basel, Switzerland. This article is an open access article distributed under the terms and conditions of the Creative Commons Attribution license (http://creativecommons.org/licenses/by/4.0/). 